Shachaf, P. (2008). Cultural diversity and information and communication technology impacts on global virtual teams: An exploratory study. Information and Management, 45(2), 131-142.

\title{
Cultural diversity and information and communication technology impacts on global virtual teams: an exploratory study
}

\author{
Pnina Shachaf ${ }^{1}$ \\ Indiana University, Bloomington
}

\begin{abstract}
Modern organizations face many significant challenges because of turbulent environments and a competitive global economy. Among these challenges are the use of information and communication technology (ICT), a multicultural workforce, and organizational designs that involve global virtual teams. Ad hoc teams create both opportunities and challenges for organizations and many organizations are trying to understand how the virtual environment affects team effectiveness. Our exploratory study focused on the effects of cultural diversity and ICT on team effectiveness. Interviews with $\mathbf{4 1}$ team members from nine countries employed by a Fortune $\mathbf{5 0 0}$ corporation were analyzed. Results suggested that cultural diversity had a positive influence on decision-making and a negative influence on communication. ICT mitigated the negative impact on intercultural communication and supported the positive impact on decision making. Effective technologies for intercultural communication included e-mail, teleconferencing combined with e-Meetings, and team rooms. Cultural diversity influenced selection of the communication media.
\end{abstract}

Key Words and Phrases

Global virtual teams, intercultural communication, information and communication technology, cultural diversity, channel selection.

\footnotetext{
${ }^{1}$ School of Library and Information Science, 1320 E. 10th St., LI 005A, Indiana University, Bloomington, IN 47405-3907, Office: (812) 856-1587, Fax: (812) 855-6166, E-mail: shachaf@indiana.edu
} 


\section{Introduction}

The use of information and communication technology (ICT), a multicultural workforce, and changing organizational models that increase worker participation have altered the nature of multinational corporations. One of the significant developments in organizational design is the introduction of team-based structures. An example is the virtual organization [14], of which virtual teams are the building blocks [73]. Members of these global virtual teams (GVTs) are often dispersed world-wide [41]. Advances in technology facilitate communication and the sharing of information among team members. By employing GVTs, organizations can combine the best expertise available for task performance regardless of geographic location, etc. As a result, use of GVTs gives organizations access to a larger pool of skills, which can reduce development time. Teams can increase organizational performance, lateral communication, and employee participation.

But in spite of their advantages, GVTs face greater communication challenges than face-to-face teams; traditional communication mechanisms are lost or distorted, and vocal and nonverbal communication cues are often missed. In addition, with members in multiple time zones, logistics are more complex. As a result, building trust among team members and overcoming feelings of isolation and detachment becomes a challenge. Thus ICT use in global organizations increases teamwork complexity and may impact its effectiveness. Finally, the culturally heterogeneous composition of many teams adds to their complexity as cultural biases may distort communication.

Researchers are trying to determine how virtuality impacts team effectiveness $[16,57]$, focusing on a variety of success predictors, such as conflict management [51], leadership [35], trust [32], communication [48], norm development [42], boundary crossing [20], creativity [53], team size [5], and technology appropriation [44]. The effect of virtual team composition on performance seems very important; e.g., cultural diversity influences virtual team effectiveness [9]. Although the literature suggests that cultural diversity is a critical predictor of effectiveness, empirical findings that support this claim are rare. Therefore, it is important to gain a better understanding of the effect of cultural diversity on team effectiveness and to understand how ICT mitigates or amplifies this influence.

\section{Literature Review}

Culture is a complex, multidimensional construct that can be studied on several levels: international, national, regional, business, and organizational. Each individual is influenced by a wide range of cultural factors: ethnic, organizational, and national. Commonly used definitions of cultural diversity include racial, sexual, organizational, professional, and national heterogeneity. Cultural diversity is here defined as heterogeneity of national cultures of team members; an individual's national culture is considered to be that of his or her country of residence.

Culture has been defined as "the collective programming of the mind which distinguishes the members of one group or category of people from another" [29]. Two important frameworks of cultural dimensions are those of Hall [26] and Hofstede [29]. These define culture according to a small number of dimensions, in which each culture 
varies, but neither of the frameworks seems sufficient to capture the complexity of culture. One of the weaknesses of a dimensional approach is the underlying assumption that few dimensions can explain beliefs and values. Studies in IS have focused on three or four dimensions and have rarely used qualitative ethnographic methods to discover the significant components of culture. However, individuals from different cultural backgrounds communicate and make decisions differently [1] and their verbal and nonverbal communication styles differ [24]. But there is a paucity of articles in this area. In 2002, Myers and Tan wrote a paper [52] that focused on national culture in IS research and initiated a call for IS researchers to conduct more in-depth case studies and ethnographies of the relationship between ICT and culture. They noted that only two studies out of 36 they had found used ethnographic methods. Our study attempted to add to the body of knowledge and we focused on the link between culture and ICT.

Researchers have identified differences in technology use and perception of task technology fit between eastern and western cultures. Lee [39] found that patterns of e-mail use vary (probably due to power distance). Massey, Hung, Montoya-Weiss, and Ramesh [47] found significant differences in the perception of task technology fit between virtual team members from the United States, Asia, and Europe. Since cultural diversity has been assumed to critically impact team effectiveness, and aspects of diversity are likely to be amplified in the virtual setting [30].

It is evident that input variables such as group composition have both direct and mediated impacts on group outcomes $[19,55]$. Previous studies of global face-to-face teams have suggested that cultural diversity has both a positive and negative influence on team effectiveness. Likewise, research into the influence of heterogeneous composition on team effectiveness in face-to-face teams produced mixed results [25]. Earley and Mosakowski, for instance, found that highly heterogeneous teams and highly homogeneous teams exhibited high levels of productivity, while moderately heterogeneous teams had lower levels. Other studies that compared heterogeneous and homogeneous teams concluded that diversity increased effectiveness $[12,13]$. The results of these studies indicated that cultural diversity increased creativity due to a wider range of perspectives, more and better ideas, and less "groupthink," and that cultural diversity therefore could increase performance. In the long run, heterogeneous teams outperformed homogeneous teams in identifying perspectives on a problem and generating alternatives [71].

On the other hand, heterogeneous face-to-face teams experience higher process losses because of communication barriers. Since cultural diversity increases the complexity, conflict, confusion, and ambiguity of communication, it sets higher challenges for leaders and members. Previous studies have found that culturally diverse groups exhibit lower levels of integration and cohesion [70]; the lack of shared mental models inhibits understanding among team members. Furthermore, the most evident aspects of miscommunication are less accuracy in communication, slower speech, and translation problems. Barna [3] suggested that there are six reasons why intercultural communication fails to create mutual understanding: false assumptions of similarity, language, nonverbal misunderstanding, the presence of misconceptions and stereotypes, the tendency to evaluate, and the high anxiety that exists. 
Research on co-located heterogeneous groups that use ICT revealed that heterogeneity and the use of technology had both advantages and disadvantages [2, 7]. Chidambaram and Kautz focused on the extent to which electronic meeting systems help define common ground; they found that some electronic meeting system structures affected diversity-reducing or increasing their impact. For example, the anonymity feature strongly reduced negative aspects of diversity, such as stereotyping, while strongly increasing participation and the meeting quality. The simultaneity feature decreased distortion in communication and collusion; it strongly increased the number of alternatives, the quality of the process and the decision. The electronic recording and display feature strongly decreased distorted communication; decreased collusion; increased cohesiveness, inclusion, and common ground; and eventually increased the quality of the process and decision. Finally, the process-structuring feature strongly increased conflict management, so that process quality increased.

Daily et al. found that groups that used group decision support systems (GDSS) outperformed those that did not. Culturally diverse groups produced a significantly higher number of non redundant, realistic ideas than homogeneous groups. Daily and Steiner found that groups using GDSS outperformed groups that did not and achieved a higher number of ideas than homogeneous groups that used it. Furthermore, heterogeneous teams that used technology had higher levels of satisfaction. Also, a collaborative conflict management style positively impacted satisfaction with the decision making process, perceived decision quality, and perceived participation of the virtual teams [56].

The purpose of our study was to ascertain how cultural diversity within GVTs impacted team effectiveness - whether the effect of cultural diversity was diluted, similar, or amplified in the virtual setting compared to a traditional setting. More specifically, we hoped to answer the questions:

1. How does cultural diversity in virtual teams influence team effectiveness?

2. How do communications technologies mediate the relationship between cultural diversity and team effectiveness?

\section{Methodology}

Our exploratory study used an interpretive approach to expand the understanding of some elements of cultural diversity and ICT that may influence GVT effectiveness. The theory was generated through an inductive method because of the lack of a comprehensive framework for conceptualizing the important elements and their relationships.

A total of 41 individuals from nine countries (France, Germany, Israel, Italy, Japan, Netherlands, Switzerland, United Kingdom, and the United States) participated in our study. Number of participants per country ranged from one to 15 . Data collection involved 41 interviews (16 face-to-face and 25 via telephone) over a nine-month period lasting from June 2002 to February 2003.

The data was collected by individual interviews with GVT members of a leading multinational Fortune 500 corporation in the computer industry. The bulk of the data 
came from ad-hoc GVT members who worked for that corporation. The corporation's top management is based in the United States but it has divisions located around the globe.

Nine of the participants in the study were team members of an ad hoc interorganizational GVT created for a research and development project and financed by the European Union under the Information Society Technologies Program. Four of them worked with the five employees of the multinational corporation but were employed by other organizations. This GVT was spread over six European countries and involved employees of seven organizations (participants from four of these were interviewed).

The interview protocol was developed with open-ended questions built upon the research questions and our review of the literature. The interviews were transcribed and interpretation of the text was performed during the analysis [50]. An inductive interpretation method was used [4]. Categories were developed from the data and then concepts from the data were sorted according to the categories. An examination of the sorted data identified patterns and relationships among concepts. Data analysis and coding began once the first interview had been transcribed and lasted until after the final interview had been transcribed. The continuous processing was combined with additional data collection. An open coding method was used for the transcriptions; the categories were developed as the material was coded. Open coding of sections of the text enabled additional codes to emerge from the data. This descriptive and interpretive coding was fine tuned during the analysis until all transcriptions were coded. For example, a "communication" code was assigned during early stages of the analysis to certain paragraphs, but as more paragraphs were added to this category the code was divided into "intercultural communication" and "informal communication." "Intercultural communication" was later divided into "verbal" and "nonverbal communication" and then subcategories were developed for each of these communication styles involved in intercultural communication (Appendix 1).

Next, pattern coding was conducted during a systematic comparison of text passages $[4,36]$. Conceptualization and theory generation occurred through a process of continuous data collection and data analysis [68]. Data analysis and coding involved constant comparative analysis, which is the heart of grounded theory. To generate theories, the capabilities of the NVIVO 1.3 software, which was designed for qualitative analysis, were used to identify co-occurring factors [8]. To identify relationships among the three key concepts, pattern coding invoked "search and retrieve" options across interviews. For example, to explore links between different types of technologies and communication subcategories, the NVIVO matrix capabilities were used to retrieve code concurrences. As a result, the relationship between face-to-face and nonverbal differences and the relationship between e-mail and verbal communication became clear. 


\section{Findings}

\section{The Impact of Cultural Diversity on GVT Effectiveness}

Cultural diversity has both positive and negative effects on GVT effectiveness. Participants stated that the negative effects of heterogeneity were due to challenges associated with intercultural communication, and that the positive effects were due to a potential for better decision making.

\section{Intercultural Communication}

The negative impacts of cultural diversity resulted from increased complexities resulting from heterogeneity and dispersion. Cultural and language differences resulted in miscommunication, which jeopardized trust, cohesion, and team identity. In the context of our study, these complexities included the higher cost of interaction and the effects of intercultural communication on miscommunication.

Participants suggested that cultural and language barriers produced communication challenges. In particular, lack of accuracy created difficulties in both written and spoken language, requiring team members to invest more time and effort in encoding and decoding messages. Thus, the cost of interaction for both senders and receivers increased. In addition, the cost of interaction was higher for both native, who had to be accurate and yet simple, and nonnative speakers. Another challenge that increased the costs of interaction was the slower pace of nonnative speakers' communication, in particular when using synchronous communication channels.

More specifically, participants reported on dimensions of intercultural communication that may have a negative impact due to cultural diversity. The different dimensions mentioned by GVT members corresponded to the four stylistic modes of verbal interaction identified by Gudykunst and Ting-Toomey: direct/indirect, succinct/elaborate, contextual/personal, and instrumental/affective. Direct/indirect style refers to the extent to which people reveal their intentions using explicit verbal communication. Americans and Israelis stated that GVT members from eastern cultures, such as Japan or China, were not direct in their communication. These team members felt that they were confused while waiting for clarification and clearer responses from Asian team members, and concluded that communicating with them was a frustrating process. The following quote illustrates this (the references for each quote consisted of the identification number assigned to each participant, the date of the interview [month/date/year], and the participant's country of residence.):

I'm a direct person...I'm not as patient with this trying to read into what people are saying. And in some cultures, looking at body language is very important. Well, how do you do that over the telephone? $(10,8 / 10 / 02$, U.S.) 
Succinct vs. elaborate style refers to the differing amount of information provided in communication. Elaborate style provided more than just the required information, and succinct style provided less verbal information while using silence and pauses.

Americans and Israelis said the Asians were succinct; these team members claimed that their Asian partners' communication did not involve enough words. They had difficulties in interpreting the silence, which caused them frustration and some misinterpretation.

The Israelis are direct but elaborate in their communication...They will have a lot of discussion about the things that they're direct about...I mean, the Israelis talk a lot, that's how it seems. They say a lot. (38, 1/22/03, U.K.)

The third difference was between the contextual and personal styles. The contextual style was formal, reflecting the social and organizational differences between people, and maintaining the social context; the personal style assumed similarity and equality. German and Japanese participants reported that English language style was more personal than their own language. They felt that when they communicated in English they could not maintain the social structure that was exhibited in their own language. Their inability to maintain the social structure was frustrating. ...because we have some cultural expressions that are more special polite expressions...But in Japan, maybe more complicated or strict expressions exist for how polite you are speaking...depends on the age of the person...so conversation is the same unless there is an older person. With [an older team member], I would speak differently. (13, 8/30/02, Japan)

The fourth difference was instrumental vs. affective-intuitive. The instrumental style was sender and goal oriented, and the affective style is receiver and process oriented. American team members perceived some of the communication incidents among Japanese to be unnecessary because these were not instrumental. The American team members did not feel these messages contained a "to do" component. This created frustration and sometimes misinterpretation by American team members when Japanese team members copied managers on the entire organizational hierarchy for a particular message. While the Japanese focused on maintaining relationships and were process oriented, the Americans felt that this act created conflict and intensified existing misunderstandings. Each of these stylistic differences contributed to miscommunication and frustration.

I don't know why they [Japanese] do, but it is cultural. It's a 'keeping people informed' mentality, and also the upper-level management does not feel that it has to act upon all these notes, which is a different mentality in the United States. (31, 10/21/02, U.S.)

In addition to verbal style differences, participants reported on nonverbal communication challenges such as cultural differences in time orientation and body language. 
I have learned [that] we don't know to interpret the body language of all the nations, and we don't express ourselves the same way, so this illusion that if you stand in front of someone you understand him better, I don't even know if it is true, because...the same gestures in different cultures mean completely different things...Until I learned that I was completely wrong, and that anything that has to do with people from other cultures I can't read. (32, 10/22/02, Israel. Translated from Hebrew)

Some members of the GVTs were from polychronic cultures such as Portugal and France, while others were from monochronic cultures such as the United States and the United Kingdom. Members of polychronic cultures tended to regard the scheduling of meetings in a more fluid way; for example, they might arrive late (or even very late). This behavior sometimes created tension with other team members who were from monochronic cultures that compartmentalized time.

In European projects...for physical meetings, we see, of course, cultural diversity. People in the North tend to be more precise with respect to time, with respect to quality. People in the South tend to be loose with time... They are not actually right on time. It's a matter of appraising time. Time is less important as you go south...In a European project, everybody knows that we have to be relaxed on that. $(34,1 / 16 / 03$, France)

It should be stressed that GVT members reported that the polychronic/monochronic difference was noticeable primarily during face-to-face meetings and occasionally during teleconferences. Team members from polychronic cultures were timelier when using virtual channels.

For some [countries], it's very important that you respond as quickly as possible. For some others, it doesn't matter; they can wait for a week later. Or for some of them, they would say, "Okay, when I respond, that's okay; it doesn't matter." But for some others, they would say, "I will send a note. I will send a reply that I cannot do it now, but I will put my reply at some point in time, later, in a few days, when they are available to respond." That's the kind of different behavior. In the UK, people are like that, sending you a note and giving you an appointment for later. (34, $1 / 16 / 03$, France)

\section{Decision-Making}

The positive impacts of team heterogeneity on team effectiveness were not associated with team intercultural communication but were due to the potential of heterogeneity and dispersion on decision making [15]. Improved decision making is made possible by using multiple points of view, increased availability of knowledge and skills, and constructive conflict. 
Participants mentioned that leveraging diverse skills and knowledge was an important consideration for improving decision making, particularly in the design and marketing of products for global markets. Pooling knowledge and skills that were located in remote sites was one particular advantage. The availability of these skills to the GVT enabled the team to perform complex tasks. Diversity in knowledge and skills improved decision making by providing additional information in the form of unique knowledge or skills. Another example was in the creation of structural conflict among subgroups during the early stages of system development. Designing a cross-functional GVT (for example, with subgroups of users and developers in the interorganizational team) facilitated this process. Input of multiple points of view in the decision-making process during the early stages of development became routine and enabled the GVT to develop a better product based on solutions that had been developed to face additional challenges. Participants suggested:

We tended to organize much more by geography, and there was a big problem because people from different labs would compete against each other...So I've changed the way I manage to functionally manage rather than site manage, which is very hard. $(9,8 / 6 / 02$, U.S.)

For example, in [this team], we have two main subgroups. One is the developmental group, and the other is the user subgroup. And we consistently build these two groups, so they will be in conflict...To reflect the conflict that happens between the market at the level of the suppliers and users. So that we have power and counter-power... but we turn this conflict into positive outcomes... We created not the conflict but the groups on purpose. They manage their own view...and so that they can express their own interests. But these interests [are] of course opposite in many ways...we build this project to have plenty of conflict. (33, 1/16/03, France)

It should be pointed out that while the participants elaborated on the negative impact of cultural diversity they discussed the positive impact only briefly. Similarly, Adler found that out of 60 participants in his study, only one saw the positive impact of cultural diversity on performance, while 20 saw a negative impact, and the others saw no impact.

\section{ICT Mediation of the Impact of Cultural Diversity on GVT Effectiveness}

GVT members use multiple technologies for communication and information sharing. Participants in our study reported on their use of e-mail, chat, e-Meetings, teleconferencing, and team room activities, in addition to face-to-face meetings. The media channels were mainly through corporate-wide use of Lotus groupware, which supports e-mail, Sametime (chat and e-Meetings), team room (shared electronic workspace), and other applications. 
Participants suggested that ICTs mitigated the negative impact of cultural diversity and enabled its positive impact. These channels helped team members bridge space and time differences. E-mail enabled improved encoding and decoding and helped members overcome differences in verbal and nonverbal styles of communication. The use of team rooms increased team identity, and the use of channel combinations allowed team members to overcome miscommunication barriers.

\section{E-mail}

Participants reported that GVT members used e-mail more than any other medium. When considering the benefits and limitations of e-mail in the context of GVTs, two aspects were important: (1) the limitations and benefits of the technology, and (2) the benefits and limitations of e-mail for intercultural communication. Obviously, e-mail cannot convey social and nonverbal cues. However, when intercultural communication was involved, some of the limitations became beneficial; the lack of nonverbal and social cues [65] reduced miscommunication due to cultural diversity.

Communicating with technology [e-mail] with people in other countries...removes some of the problems...you don't have all the cultural, physical aspects of communications. You know, the way you speak to a Japanese is not the way you speak to an Arab is not the way you speak to an American, from the point of view of the distance you have to keep, the way you look at them, the way you express feeling, etc. when you just type a text in an e-mail or a chat system...all that disappears, there is just the plain text there. $(1,7 / 17 / 02$, U.S.)

The use of e-mail reduced miscommunication due to language differences among GVT members. Participants suggested that non-native English speakers were able to express themselves better through e-mail than by talking.

The Japanese, writing is okay for us, but speaking or hearing is tough for us. So writing...and sending the messages...that really helps us for the communication. (13, 8/30/02, Japan)

E-mail provided native and nonnative speakers with the ability to improve the accuracy of the message by using spell checkers and going over the message before it was sent. Participants said:

I would rather use e-mail because...I can use the spell checking...(16, 9/10/02, Israel. Translated from Hebrew).

...because in e-mail, you tend to...read over and want to be explicit so I go back, and say this, this and this. (2, 7/24/02, U.S.).

The result was improved accuracy and easier decoding. This benefit of text-based computer mediated communictaion for diverse participants in asynchronous learning networks was pointed out previously [27]. Also, local group efforts in encoding and 
decoding e-mails helped to improve accuracy. As one of the French team member claimed:

I knew that it would be very important that all of the information that we write in English is not ambiguous at all. So...I spent a lot of time writing messages in English, trying to make sure that these messages would be clear enough and not ambiguous...I would prepare an e-mail that I would deliver to the mailing list [of the entire GVT], and before sending this e-mail to the mailing list, I would ask my teammates [in the same location] if they agree with the statement. (42, 2/21/03, France)

Finally, e-mail also eliminated the vocal noise of nonnative speakers' accents. With the Japanese and the Chinese...even if it begins on the phone, eventually we ask them to do it all via e-mail. Because we just don't understand what they are saying. $(16,9 / 10 / 02$, Israel. Translated from Hebrew)

Thus, miscommunication due to language barriers was reduced in GVTs that conducted most of their work using e-mail, which did not eliminate the negative impact of differences in verbal style, but did reduce it. This was due to the use of "e-mail style," which is formal, technical, and structured with short and precise sentences. In it, each message contains only one message that is embedded in its context, with high accuracy and direct style.

One learns to use very simple language and short sentences...For example, in an e-mail...you will not include more than one idea...If you have three different things to say you will do it in three separate messages...Since I observed it with the Indian, the Japanese, everyone learns slowly to behave in a universal way. $(32,10 / 22 / 02$, Israel.

Translated from Hebrew)

I think the Japanese tend to be more direct in e-mail or attempt to be. Because for one thing, Japanese, or Asians, are just, they don't like to say "no." (10, 8/10/02, U.S.)

In addition, e-mail gave the text in a sequence that did not include pauses for interpretation.

One of the things that I am doing is to listen, which is very difficult with the Japanese. I can't get to [understand] them at all. I listen enough to know that I don't know anything. With the Japanese I know that I have no clue about how to communicate with them well...The Japanese they simply don't talk, you have nothing to listen to. So you would learn how to exchange messages with them. $(15,7 / 22 / 02$, Israel. Translated from Hebrew) 
Straightforward text helped overcome differences between succinct and elaborate verbal styles.

...e-mail, usually lack context...One learns over time not to assume that the other one understands what the context is. So you will repeat all of the context, and then you add your own sentence... In any team...any culture...you learn that you have to provide the context in e-mail. (32, 10/22/02, Israel. Translated from Hebrew)

In addition, balancing formality of the message in written English reduced personal/contextual verbal differences. As a participant said:

If it got very formal, in English, I have a problem, with written language to really use very, very formal English. The English language is by nature very informal compared to German...In Germany, I am used to writing more formally than in the English language...When I'm talking about formal, I'm talking about the style. I'm not talking about content. (36, 1/22/03, Germany)

E-mail mitigated the negative impact of differences in verbal and nonverbal style, thus reducing miscommunication. In addition, e-mail reduced the effect of different time zones. Differences between polychronic and monochronic cultures manifested themselves mainly in face-to-face meetings. E-mail reduced the challenges associated with cultural diversity. The rehearsability or editability of e-mail helped overcome language barriers. Email as a lean medium did not allow accents and nonverbal misinterpretations to occur. Similarly, the relative absence of social cues facilitated intercultural communication.

\section{Teleconferencing}

Participants reported that in addition to e-mail, GVT members used teleconferencing frequently. Participants suggested that language encoding was more difficult via phone than in face-to-face communication or e-mail. Vocal cues were distracting and unfamiliar accents often created miscommunication. Nevertheless, teleconferencing mitigated some of the negative impacts and supported the positive impacts of cultural diversity.

Participants described ways they overcome the challenges of teleconferencing. One way they avoided miscommunication was to avoid teleconferencing with team members who spoke with unfamiliar accents. Another tactic included restating arguments and agreements and creating written summaries of agreements during a teleconference or immediately afterwards. Participants also enlisted help from their local groups when encoding or decoding messages. Finally, using one channel of communication to complement another created new capabilities for intercultural communication; for example, teams used Lotus Sametime e-Meetings during group teleconferences. The following quotes illustrate these tactics in the words of the participants: 
...so they [Japanese] would restate...So let's say that either [XXX] which is [a] manager, or there's a guy [XXX] who has good English speaking. He would basically say, "This is what we're saying." Number one, they would tend to [put] it out a little more crisply, and second of all, their English was better, and they would speak somewhat more slowly and clearly. $(10,8 / 10 / 02$, U.S.)

In their [with Japanese] case I find that it helps to reinforce it with an e-mail afterwards...I sometimes use e-mail as an adjunct to talking as well so if they call me on the phone...at the end of the call, I might sit down and write them an e-mail saying, "This is what I understood from our conversation." Because by writing it down, they can then review it, think about it, spend time with it. $(4,7 / 29 / 02$, U.S.)

But most of the time [during teleconferences] we sit all together. We also help each other to get the full picture.... what we understand and what we don't understand...We will turn the phone to mute, and we will say, "What did he mean?" (15, 9/22/02, Israel. Translated from Hebrew)

We could do...an e-Meetings...share part of my desktop with someone else. And this is typically what we set up when we talk with the [Japanese] guys...As we talk about issues, we'll type in the result or whatever, the resolution, and we save all this stuff in a database, which we all have access to...As we come to a resolution, I'll start typing there, and I'm hoping that that will help them verify the result and that we're communicating effectively so they can see me typing the result on their screen...Anything visual to sort of help guide the conversation or provide an outline that they can read, it helps them, it helps us all. $(12,8 / 30 / 02$, U.S.)

Creating new capabilities for communication increased individual and team effectiveness. Synchronous written documents helped teams overcome challenges associated with spoken language, and this enabled teams to overcome challenges associated with asynchronous and lean written communication. E-Meetings enabled teams to use written language to offset the amplified miscommunication caused by unfamiliar accents. It also supported effective communication by allowing members to restate, in a written document, agreements made in the conversation. The combination of teleconferencing and e-Meetings enabled synchronous communication that was richer than either technology by itself.

\section{Team Rooms}

A team room is an electronic shared group workspace. According to participants' reports, effective GVTs often employed team rooms. GVTs that used them experienced decreases in communication distortion and increases in team cohesiveness, inclusion, 
and common ground. The use of team rooms enabled the creation of team identity and helped overcome difficulties associated with dispersion and cultural diversity. The team room supported team identity by providing members with a sense of belonging to the GVT. Restriction of access to the team room to members enabled the group to differentiate itself from other teams or organizations. In addition, the team room served as a shared repository of documents and discussions among team members. As one participant said:

Above e-mail and telephone, team rooms have changed the way extended, diverse teams work...The great thing about that is, that's almost an electronic version of trust...First off, team identity...is very important... The only people who have access to that are the people on the team or the people that the team has decided collectively that it's okay to have access. So you must be part of us, or you wouldn't have this good little benefit here...Yes, an effective team, one of the very first things they will do is create that team room, set the distribution list, set the policies on what will be public space, what will be private space, what will be administered by a common point, what will be open to everyone... Because it reinforces the membership of the team. If you think about it, it reinforces what it means to be on that team. It's another benefit to belong. $(7,7 / 30 / 02$, U.S.)

Team room's asynchronous nature, archiving capabilities, and restricted accessibility were useful characteristics for GVTs. The restricted virtual territory was a critical characteristic of team rooms that enable members to bridge geographical dispersion and cultural differences.

\section{Chat}

GVT members reported also on their use of Lotus Sametime chat. They typically used it while engaged in other activities, such as meetings or teleconferences. In the intercultural context of GVTs, textual chat has the potential for mitigating the impact of cultural diversity on team effectiveness. Like e-mail, chat eliminated nonverbal differences, etc. Yet maybe because of the synchronous nature of chat, participants did not perceive it to be preferable for intercultural communication. Moreover, users considered chat to be mostly for informal and spontaneous communication. Participants reported chat use among GVT members who shared the same social group and had high social proximity (i.e., proximity of members collocated, at the same line of command or the hierarchy, or who "know one another."). The informal and synchronous nature of chat amplifies differences among GVT members that do not share the same location, time zone, culture, and language.

Therefore, chat amplifies the negative effect of cultural diversity on team effectiveness by stressing the socio-cultural context but it reduces the negative effect of cultural diversity on team effectiveness by reducing nonverbal differences as a cause for miscommunication. The following quotation illustrates this: 
I like Sametime because...people...figure they need to know you before they Sametime you...Because Sametime is an interrupt, an immediate interrupt. I would not Sametime somebody that I had never met before... or talked to them on the phone and they knew what my job is and why I would even bother them...Typically, it's limited to your most immediate, inner circle of people you work with... $(10,8 / 10 / 02$, U.S.)

Thus, when compared to face-to-face communication, the use of ICT reduces the challenges associated with cultural diversity and decision making. Therefore, it is possible that the selection and implementation of particular ICTs could facilitate GVT communication and decision making.

\section{Channel Selection}

It is possible that the use of an appropriate channel improves GVT effectiveness. Participants in our study reported on contingencies that influenced their channel selection, such as task $[10,11,40]$, social and physical proximity, sender and receiver accessibility to a channel, individual preferences regarding a channel [64], assumptions or knowledge about the receiver's preferences, and-when replying-the initial channel used. The use of ICTs can be partially explained by media richness theory, social influence theory, and social presence theory [66]. "Many elaborations have been suggested ... such as situational constraints, symbolic uses and values, initiator-receiver distinctions, sequences of media use, effects of time and experience, and social information-processing" [61]. It was suggested that richness or leanness is not an inherent property of e-mail, but an emergent property of the interaction of the email medium with its organizational context [38]. Likewise, Markus [45] stated that the social context was more important than the medium for communication effectiveness. Even a lean medium can be rich if the organizational context supports it.

Of particular relevance to our study was the impact of social proximity and culture on media choice [67]. Social proximity influenced the preferred formality and synchronicity of the channel. For example, members with high social proximity could use a wide range of channels, while low social proximity precluded synchronous and informal channels. Similarly, when vertical or horizontal organizational differences were significant, employees who were lower ranked or dispersed were more likely to initiate (upward) communication via formal and asynchronous channels. In a similar way, individuals who were unfamiliar with each other selected channels that were perceived to be widely used. The following quote from a participant illustrates this.

The level of familiarity we have will have some effect [on media selection]. Most of the time if it is someone we never talked to, or it is the first time, or we are distant from each other, in a different hierarchical level, in other words he is a top executive or alike, or due to any other reason that creates distance, then I would rather use e-mail since it is more formal; the language is more formal. I can use the spell checker...If it is someone closer to me-closer might be that we have 
been talking a lot, or we are at the same league, or that we share physical proximity, or due to any other reason that makes me feel that this person is closer to me-I could easily use the chat. $(16,9 / 10 / 02$, Israel.

Translated from Hebrew)

The influence of cultural differences on media choice was an important contingency. Participants suggested that for intercultural communication, cultural differences limited the range of potential effective media channels. Participants suggested that e-mail was frequently selected for intercultural communication.

So I think if you go from a western kind of culture to some of these other ones that are different, a little different, you have to...your communication style, and the medium you use would change.... [ this is in addition to] for instance if I have a quick question I would send them a chat. If that question would then have a complicated answer, I would pick up the phone. Because when you need to communicate and be clear and be sure that there is clarity, you talk [by] phone. $(2,7 / 24 / 02$, U.S.)

While the impact of social proximity and culture on media choice is important in the context of our study, other contingencies influenced media choice, such as the task at hand.

Table 1 summarizes the findings of our study.

Table 1. Summary of findings

\begin{tabular}{|c|c|c|c|}
\hline Impacts & & ICT Role & Outcomes \\
\hline \multirow[t]{4}{*}{$\begin{array}{l}\text { Positive } \\
\text { impacts of } \\
\text { cultural } \\
\text { diversity }\end{array}$} & $\begin{array}{l}\text { Leverage diverse knowledge } \\
\text { and skills to improve } \\
\text { outcomes of decision making, } \\
\text { and to develop a global } \\
\text { product }\end{array}$ & Enable & $\begin{array}{l}\text { Improve outcomes of } \\
\text { decision making and } \\
\text { performance (compared } \\
\text { with collocated } \\
\text { homogeneous teams) }\end{array}$ \\
\hline & $\begin{array}{l}\text { Concurrent engineering to } \\
\text { reduce time to market }\end{array}$ & Enable & $\begin{array}{l}\text { Improve performance (time } \\
\text { to market) }\end{array}$ \\
\hline & $\begin{array}{l}\text { Software engineering reduces } \\
\text { dependency on how each } \\
\text { component functions to } \\
\text { improve integration of } \\
\text { components }\end{array}$ & Enable & $\begin{array}{l}\text { Improve performance } \\
\text { (compared with collocated } \\
\text { homogeneous teams) }\end{array}$ \\
\hline & Constructive conflict & Enable & $\begin{array}{l}\text { Improve outcome of decision } \\
\text { making and performance } \\
\text { (compared with collocated } \\
\text { homogeneous teams), but } \\
\text { reduce satisfaction }\end{array}$ \\
\hline
\end{tabular}




\begin{tabular}{|c|c|c|c|}
\hline \multirow[t]{3}{*}{$\begin{array}{l}\text { Negative } \\
\text { impacts of } \\
\text { cultural } \\
\text { diversity }\end{array}$} & $\begin{array}{l}\text { Differences in non-verbal } \\
\text { styles create } \\
\text { miscommunication }\end{array}$ & Eliminate & $\begin{array}{l}\text { Improve communication, } \\
\text { satisfaction, and } \\
\text { performance (compared } \\
\text { with face-to-face } \\
\text { heterogeneous teams that } \\
\text { do not use ICT) }\end{array}$ \\
\hline & $\begin{array}{l}\text { Differences in verbal style } \\
\text { create miscommunication }\end{array}$ & Mitigate & $\begin{array}{l}\text { Improve communication, } \\
\text { satisfaction, and } \\
\text { performance (compared } \\
\text { with face-to-face } \\
\text { heterogeneous teams that } \\
\text { do not use ICT) }\end{array}$ \\
\hline & $\begin{array}{l}\text { Language differences create } \\
\text { miscommunication due to lack } \\
\text { of accuracy }\end{array}$ & Mitigate & $\begin{array}{l}\text { Improve communication, } \\
\text { satisfaction, and } \\
\text { performance (compared } \\
\text { with face-to-face } \\
\text { heterogeneous teams that } \\
\text { do not use ICT) }\end{array}$ \\
\hline
\end{tabular}

\section{Conclusions and Implications}

The purpose of our study was to develop an empirically grounded model. It is illustrated in Figure 1.

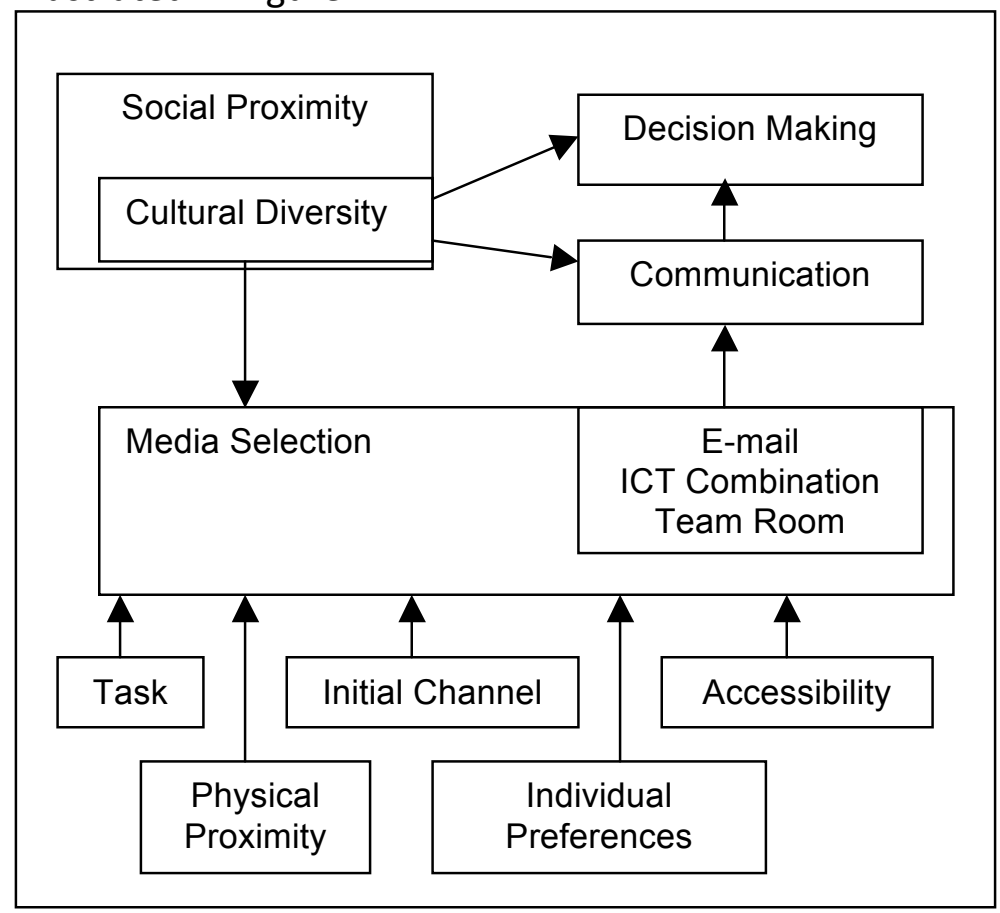

Figure 1. The impact of cultural diversity and information and communication technology on decision making and communication. 
ICT is a tool that facilitates the process of boundary-crossing to overcome the challenges presented by remote and culturally diverse team members. In particular, our study indicated that ICT mitigated the negative impact of intercultural miscommunication. Although the intended purpose of ICT was to overcome geographical and time zone differences, ICT supported the creation and maintenance of team identity by the use of team rooms that decrease distorted communication (by capturing decisions in a shared database) while increasing team cohesiveness, inclusion, and common ground.

One of our main findings was that cultural diversity of team members was a major factor influencing media selection. Combination of channels was one way in which ICT could operate better than in face-to-face meetings. Our study also confirmed the tendency of team members to perceive diversity to be negative.

Differences in language, verbal styles, and nonverbal styles influenced team effectiveness; nonverbal differences mainly affected face-to-face communication. Information and communication technologies mitigated the negative impact of cultural diversity on team effectiveness while supporting the positive impact.

Based on our work, multinational corporations use e-mail for intercultural communication, with teleconferencing coming second; face-to-face meetings are also common. Some patterns in verbal and nonverbal communication styles are amplified in some channels (e.g., distortion of accents when using a telephone), and others are mitigated or eliminated via other channels (e.g., nonverbal differences when using e-mail). Some of the differences in style and language that cause miscommunication are reduced by e-mail, while others (e.g., nonverbal cues) are eliminated. Except for face to face, the media channels of our study mitigated the negative effects of cultural diversity and dispersion.

One of the main limitations of this study is that results were derived from one organization. Assumptions about the transferability of these findings to other industries and corporations should be made with caution.

Another limitation is in its sample, which included only a few members from some cultures (e.g., Japan, France, and Germany) and many from others (U.S. and Israel). The findings were probably skewed and primarily reflected perceptions of members from these two cultures. Also members of eastern cultures were barely represented in our sample. A similar limitation lies in the selection of quotations used to illustrate the various points; most were from interviews with native English speakers.

Despite these limitations, this study contributed to research theory and management practice.

Dispersed and diverse GVTs that operate using mostly mediated communication need to be able to master a wide repertoire of channels and to be able to use them effectively, but they also need face-to-face meetings. Training in intercultural communication should focus more on differences in verbal styles than on nonverbal differences. GVT members should be able to communicate effectively in all contexts. When team members are dispersed, e-mail is an effective channel and GVTs should use e-mail with synchronous textual chat or screen sharing (e.g., e-Meetings), while engaged 
in team teleconferences. A team room also supports the creation and maintenance of team identity across sites, time zones, and cultures, as well as team viability.

The implications of our study for systems design emerge mainly from uses of multiple media and combinations of media. Collaborative group systems should incorporate possibilities for using multiple media channels and separate channels. ICT combination requires that systems enable users to customize and mix channels according their different needs in different situations.

\section{Acknowledgement:}

Thanks to Barbara B. Moran, my dissertation advisor, and to Evelyn H. Daniel, Benson Rosen, Paul Solomon, and Barbara B. Wildemuth my dissertation committee for their helpful comments, suggestions, and guidance. Thanks for the anonymous reviewers for their useful suggestions. 


\section{References}

[1] N.J. Adler, International Dimensions of Organizational Behavior, 3rd ed., PWS-Kent, Boston, MA, 1997.

[2] W.N. Anderson, Cultural Values and Communication Mode: A Study of Culturally Homogeneous and Culturally Heterogeneous Groups, Unpublished doctoral dissertation, Rutgers, The State University of New Jersey, Newark, 2000.

[3] L.M. Barna, Stumbling blocks in intercultural communication, in L.A. Samovar, R.E. Porter (Eds.), Intercultural Communication: A Reader, 4th ed., Wadsworth Publishing Company, Belmont, CA, 1985, pp. 330-337.

[4] B.L. Berg, Qualitative Research Methods for the Social Sciences, 4th ed., Allyn \& Bacon, Needham Heights, MA, 2001.

[5] E. Bradner, G. Mark, T.D. Hertel, Effects of team size on participation, awareness, and technology choice in geographically distributed teams, in Proceedings of the 35th Hawaii International Conference on Systems Sciences, Big Island, Hawaii, January 7-10, 2002.

[6] B.K. Buckley, A Model of Virtual Organization Effectiveness: Optimizing the Outcomes of Interorganizational Project Teams. Unpublished doctoral dissertation, The George Washington University, Washington, DC, 2000.

[7] L. Chidambaram, J.A. Kautz, Defining common ground: managing diversity through electronic meeting systems, in Proceedings of the Fourteenth International Conference on Information Systems, Orlando, Florida, December 58, 1993, pp. 1-11.

[8] A. Coffey, B. Holbrook, P. Atkinson, Qualitative data analysis: technologies and representations, Sociological Research Online 1(1), 1996. http://www.socresonline.org.uk/socresonline/ 1/1/4.html

[9] G. Dafoulas, L. Macaulay, Investigating cultural differences in virtual software teams, The Electronic Journal on Information Systems in Developing Countries 7(4), 2001, pp. 1-14.

[10] R.L. Daft, R.H. Lengel, Organizational information requirements, media richness and structural design, Management Science 32 (5), 1986, pp. 554-572.

[11] R.L. Daft, R.H. Lengel, L,K Trevino, Message equivocality, media selection, and manager performance: implications for information systems, MIS Quarterly 11(3), 1987, pp. 355-366. 
[12] B.F. Daily, R.L. Steiner, The influence of group decision support systems on contribution and commitment levels in multicultural and culturally homogeneous decision-making groups, Computers in Human Behavior 14 (1), 1998, pp. 147-162.

[13] B. Daily, A. Whatley, S.R. Ash, R.L. Steiner, The effects of a group decision support system on culturally diverse and culturally homogeneous group decision making, Information \& Management 30, 1996, pp. 281-289.

[14] W.H. Davidow, M.S. Malone, The Virtual Corporation: Structuring and Revitalizing the Corporation for the 21st Century, Harper Collins, New York, 1992.

[15] A.R. Dennis, J.S. Valacich, Rethinking media richness: toward a theory of media synchronicity, in Proceedings of the 32nd Hawaii International Conference on System Science, Maui, Hawaii, January 5-8, 1999.

[16] G. DeSanctis, M.S. Poole, Transition in teamwork in new organizational forms. Advances in Group Processes 14, 1997, pp. 157-176.

[17] D. Duarte, N. Snyder, Mastering Virtual Teams: Strategies, Tools, and Techniques That Succeed, Jossey-Bass, San Francisco, CA, 2001.

[18] L. Dube, G. Pare, Global virtual teams, Communications of the ACM 44(12), 2001, pp. 71-73.

[19] P.C. Earley, E. Mosakowski, Creating hybrid team cultures: an empirical test of transnational team functioning, Academy of Management Journal 43(1), 2000, pp. 26-49.

[20] J.A. Espinosa, J.N. Cumming, J.M. Wilson, B.M. Pearce, Team boundary issues across multiple global firms, Journal of Management Information Systems 19(4), 2003, pp. 157-190.

[21] R. Evaristo, The management of distributed projects across cultures, Journal of Global Information Management 11(4), 2003, pp. 58-70.

[22] S. Furst, R. Blackburn, B.Rosen, Virtual teams: a proposed research agenda, Information Systems Journal 9(4), 1999), pp. 249-269.

[23] B. Glaser, A. Strauss, The Discovery of Grounded Theory: Strategies for Qualitative Research, Aldine, Chicago, 1967. 
[24] W.B. Gudykunst, S. Ting-Toomey, S. Culture and Interpersonal Communication, Sage Publications, Newburry Park, CA, 1988.

[25] R.Z. Guzzo, M.W. Dickson, Teams in organizations: recent research on performance and effectiveness, Annual Review of Psychology 47(1), 1996, pp. 307-338.

[26] E.T. Hall, The Dance of Life. Garden City, NY, Anchor Press/Doubleday, 1983.

[27] S.R. Hiltz, Collaborative learning in a virtual classroom, in: Proceedings of the Conference on Computer-Supported Cooperative Work, Portland Oregon, Sept 26-28, 1988, pp. 282-290.

[28] A.B. Hollingshead, J.E. McGrath, M. O'Connor, Group task performance and communication technology: a longitudinal study of computer-mediated versus face-to-face work groups, Small Group Research 24(3), 1993, pp. 307-324.

[29] G.H. Hofstede, Cultures and Organizations: Software of the Mind, McGraw-Hill, London, 1991.

[30] G.J. Hofstede, A. Vermunt, M. Smits, N. Noorderhaven, Wired international teams: experiments in strategic decision making by multicultural virtual teams, in Proceedings of the 5th European Conference on Information Systems, 1997, vol. I, pp. 321-336.

[31] S.L. Jarvenpaa, K. Knoll, D.E. Leidner, Is anybody out there? Antecedents of trust in global virtual teams, Journal of Management Information Systems 14(4), 1998, pp. 29-64.

[32] S.L. Jarvenpaa, D.E. Leidner, Communication and trust in global virtual teams, Organization Science 10(6), 1999, pp. 791-815.

[33] S.L. Jarvenpaa, T.R. Shaw, D.S. Staples, Toward contextualized theories of trust: the role of trust in global virtual teams, Information Systems Research 15(3), 2004, pp. 250-267.

[34] P. Kanawattanachai, Y. Yoo, Dynamic nature of trust in virtual teams, Journal of Strategic Information Systems 11, 2002, pp. 187-213.

[35] T.R. Kayworth, D.E. Leidner, Leadership effectiveness in global virtual teams, Journal of Management Information Systems 18(3), 2001, pp. 7-40. 
[36] U. Kelle, Theory building in qualitative research and computer programs for the management of textual data, Sociological Research Online, 2(2), 1997. http://www.socresonline.org.uk/socresonline/2/2/1.html.

[37] B.L. Kirkman, B. Rosen, C.B. Gibson, P.E. Tesluk, S.O. McPherson, Five challenges to virtual team success: lessons from Sabre, Inc., The Academy of Management Executives 16(3), 2002, pp. 67-69.

[38] A. Lee, Electronic mail as a medium for rich communication: an empirical investigation using hermeneutic interpretation, MIS Quarterly 18(2), 1994, pp. 145-157.

[39] O. Lee, Cultural differences in e-mail use of virtual teams: a critical social theory perspective, Cyberpsychology \& Behavior 5(3), 2002, pp. 227-232.

[40] R.H. Lengel, R.L. Daft, The selection of communication media as an executive skill, Academy of Management Executives 2(3), 1988, pp. 225-232.

[41] J. Lipnack, J. Stamp, Virtual Teams: Reaching Across Space, Time and Organizations with Technology, John Wiley \& Sons, New York, 1997.

[42] A. Majchrzak, R.E. Rice, N. King, A. Malhotra, S. Ba, Development And Adaptation Of Inter-Organizational Virtual Team Norms Using Collaborative Technology, 1999. http://www.cogtech.org/CT99/ Rice1.htm.

[43] A. Majchrzak, R.E. Rice, N. King, A. Malhotra, S. Ba, Computer-mediated inter-organizational knowledge-sharing: insights from a virtual team innovating using a collaborative tool, Information Resources Management Journal 13(1), 2000, pp. 44-53.

[44] A. Majchrzak, R.E. Rice, A. Malhotra, N. King, S. Ba, Technology adaptation: the case of a computer-supported inter-organizational virtual team, MIS Quarterly 24(4), 2000, pp. 569-600.

[45] L. Markus, Electronic mail as the medium for managerial choice, Organization Science 5, 1994, pp. 502-527.

[46] L.L. Martins, L.L. Gilson, M.T. Maynard, Virtual teams: what do we know and where do we go from here? Journal of Management 30(6), 2004, pp. 805-835.

[47] A. Massey, C.Y. Hung, M. Montoya-Weiss, V. Ramesh, When culture and style aren't about clothes: perceptions of task-technology "fit" in global virtual teams, in: Proceedings of GROUP '01, Boulder, CO, September 30-October 3, 2001, pp. 207-213. 
[48] L.M. Maznevski, K.M. Chudoba, Bridging space over time: global virtual team dynamics and effectiveness, Organization Science 11(5), 2000, pp. 473-492.

[49] P.L. McLeod, S.A. Lobel, The effects of ethnic diversity on idea generation in small groups, Academy of Management Annual Meeting Best Papers Proceedings, 1992, pp. 227-231.

[50] M.B. Miles, M.A. Huberman, Qualitative Analysis: An Expanded Sourcebook, 2nd ed., Sage, Thousand Oaks, CA, 1994.

[51] M.M Montoya-Weiss, A.P. Massey, M. Song, Getting it together: temporal coordination and conflict management in global virtual teams, Academy of Management Journal 44(6), 2001, pp. 1251-1262.

[52] M.D. Myers, F.B. Tan, Beyond models of national culture in information systems research, Journal of Global Information Management 10(1), 2002, pp. 24-32.

[53] J.E. Nemiro, Creativity in Virtual Teams. Unpublished doctoral dissertation, Claremont Graduate University, California, 1998.

[54] J.E. Nemiro, The creative process in virtual teams, Creativity Research Journal 14(1), 2002, pp. 69-83.

[55] J.G. Oetzel, Self-construals, communication processes, and group outcomes in homogeneous and heterogeneous groups, Small Group Research 32(1), 2001, pp. 19-54.

[56] S. Paul, P. Seetharaman, I. Samarah, P.P. Mykytyn, Impact of heterogeneity and collaborative conflict management style on the performance of synchronous global virtual teams, Information \& Management 41(3), 2004, pp. 303-321.

[57] D.J. Pauleen, Lessons learned crossing boundaries in an ICT-supported distributed team, Journal of Global Information Management 11(4), 2003, pp. 1-19.

[58] D.J. Pauleen, P. Yoong, Facilitating virtual team relationships via Internet and conventional communication channels, Internet Research: Electronic Networking Applications and Policy 11(3), 2001, pp. 190-202.

[59] D.J. Pauleen, P. Yoong, Relationship building and the use of ICT in boundary-crossing virtual teams: a facilitator's perspective, Journal of Information Technology 16(4), 2001, pp. 205-220. 
[60] G. Piccoli, B. Ives, Trust and the unintended effects of behavior control in virtual teams, MIS Quarterly 27(3), 2003, pp. 365-395.

[61] R.E. Rice, J. D’Ambra, E. More, Cross-cultural comparison of organizational media evaluation and choice, Journal of Communication 48(3), 1998, pp. 3-26.

[62] S. Sarker, R. Grewal, S. Sarker, Emergence of leaders in virtual teams: what matters? in: Proceedings of the 35th Hawaii International Conference on Systems Sciences, Big Island, Hawaii, January 7-10, 2002.

[63] E.H. Schein, Organizational culture and leadership, 2nd ed., Jossey-Bass, San Francisco, CA, 1992.

[64] J. Schmitz, J. Fulk, Organizational colleagues, media richness, and electronic mail, Communication Research 18(4), 1991, pp. 487-523.

[65] J.A. Short, E. Williams, B. Christie, The social psychology of telecommunications. John Wiley \& Sons, New York, 1976.

[66] L. Sproull, S. Keisler, Reducing social context cues: electronic mail in organizational communication, Management Science 32(11), 1986, pp. 1492-1513.

[67] P. Shachaf, N. Hara, Behavioural complexity theory of media selection: a proposed theory for global virtual teams. Journal of Information Science 33(1), 2007, pp. 63-74.

[68] A. Strauss, J. Corbin, Grounded theory methodology, in N.K. Denzin and Y.S. Lincoln (eds.), Handbook of Qualitative Research, Sage, Thousand Oaks, CA, 1994, pp. 273-285.

[69] G. Walsham, Cross-cultural software production and use: a structurational analysis, MIS Quarterly 26(4), 2002, pp. 359-380.

[70] W.E. Watson, K. Kumar, Differences in decision making regarding risk taking: a comparison of culturally diverse and culturally homogeneous task groups, International Journal of Intercultural Relations 16, 1992, pp. 53-65.

[71] W.E. Watson, K. Kumar, L.K. Michaelson, Cultural diversity's impact on interaction process and performance: comparing homogeneous and diverse task groups, Academy of Management Journal 36(30), 1993, pp. 590-602.

[72] M.B. Watson-Manheim, F. Belanger, Exploring communication-based work processes in virtual work environments, in Proceedings of the 35th Hawaii 
International Conference on Systems Sciences, Big Island, Hawaii, January 7-10, 2002.

[73] M.B. Watson-Manheim, K.M. Chudoba, K. Crowston, Discontinuities and continuities: a new way to understand virtual work, Information Technology and People 15(3), 2002, pp. 191-209. 


\section{Appendix 1: Coding Scheme}

1. Type of technology
a. Teleconference
b. Email
c. FTF
d. Team room
e. Sametime (chat \& e-meeting)
f. Videoconference
g. ICT combinations
h. Collaborative task technology

2. Cultural diversity
a. National
b. Language

3. Geographical dispersion and time zone

4. Boundary spanning

5. Effectiveness
a. Viability
b. Performance
c. Satisfaction

6. Processes

a. Communication

i. Intercultural

1. Verbal
a. Direct/indirect
b. Succinct/elaborate
c. Contextual/personal
d. Instrumental/affective

2. Non-verbal
a. Time orientation
b. Body language

ii. Informal

iii. Cost of interaction

b. Conflict

c. Leadership

d. Media selection

i. Task

ii. Individual preferences

iii. Social proximity

iv. Physical proximity

v. Assumptions or knowledge about the receiver's preferences

vi. Initial channel (reply)

vii. Accessibility

e. Decision making 
i. Leveraging diverse skills and knowledge

ii. The creation of structural conflict

f. Software engineering and quality \& concurrent engineering and reduced time to market. 